\title{
A Clean Cut: Minimally Invasive Mitral Valve Replacement after Heart Transplantation
}

\author{
Jamila Kremer $^{1 \text { (1) }}$ Sameer Saeed Ahmed Al-Maisary ${ }^{1}$ Gábor Szabó ${ }^{1}$ \\ ${ }^{1}$ Department of Cardiac Surgery, Universitatsklinikum Heidelberg \\ Chirurgische Klinik, Heidelberg, Germany \\ Thorac Cardiovasc Surg Rep 2019;8:e27-e29.

\begin{abstract}
Address for correspondence Jamila Kremer, MD, Department of Cardiac Surgery, Universitatsklinikum Heidelberg Chirurgische Klinik, Im Neuenheimer Feld 110, Heidelberg 69120, Germany (e-mail: jamila.kremer@med.uni-heidelberg.de).
\end{abstract}

\author{
Abstract \\ Keywords \\ - heart transplantation \\ - heart valve surgery \\ - minimally invasive \\ surgery; includes port \\ access \\ minithoracotomy \\ - reoperation
}

A 50-year-old female presented with progressive heart failure due to obstruction of the mitral valve after heart transplantation in 2008. Through the occlusion catheter (IntraClude Intra-Aortic Occlusion Device), aortic cross-clamping, antegrade cardioplegia, and aortic root venting were performed.

Our case reports the first published study on minimally invasive mitral valve replacement for valve stenosis through intraluminal aortic clamping. The hazard of traumatic injuries can be reduced by avoiding resternotomy and circumventing adhesions between the aorta and the pulmonary artery after heart transplantation. Minimally invasive valve surgery is a safe and effective method with regard to short- and longterm results, especially in redo operations.

\section{Introduction}

Fifty years after the first heart transplantation (HTX), posttransplant survival is continuously improving. The mean survival in adult patients is 10.7 years; pediatric patients present a mean survival of 16.1 years. Main causes of death remain primary graft failure, infections, and multiorgan failure. ${ }^{1}$ With better survival rates, the incidences of cardiac pathologies such as cardiac allograft vasculopathy and valvular diseases will occur more often.

We report on a patient with mitral valve (MV) stenosis 10 years after successful HTX. We performed an MV replacement due to severe atrioventricular valve degeneration through a minimally invasive approach through right thoracotomy.

\section{Case Report}

A 50-year-old female presented with progressive heart failure due to obstruction of the MV after an uneventful HTX for dilative cardiomyopathy in October 2008. Initial postoperative echocardiography showed normal pump function and no signs of rejection.

(D)Jamila Kremer's ORCID is https://orcid.org/0000-0002-46606660.

received

March 21, 2019

accepted after revision

May 30, 2019
Standard immunosuppression regime consisted of a combination of prednisone, mycophenolate, and tacrolimus. However, due to persistent diarrhea, mycophenolic acid was changed in benefit of everolimus in 2009. Since 2010, the patient has been under immunosuppressive treatment with tacrolimus and azathioprine.

In 2012, doming of the MV with mild stenosis was detected. An elective balloon valvuloplasty procedure for MV stenosis in 2018 (valve orifice area of $1.3 \mathrm{~cm}^{2}$, peak pressure gradient [PPG] 24 of $\mathrm{mm} \mathrm{Hg}$, mean pressure gradient (MPG) of $14 \mathrm{~mm}$ $\mathrm{Hg}$ ) was unsuccessful. The patient was admitted for surgical valve replacement and deobstruction of the left ventricular outflow tract (LVOT) (PPG of $35 \mathrm{~mm} \mathrm{HG}$, MPG of $19 \mathrm{~mm} \mathrm{Hg}$ ) (-Fig. 1).

Repeated coronary angiography showed a known LCX (left circumflex artery) stenosis aggravated from $25 \%$ (since HTX) to 50 to $75 \%$, and a percutaneous transluminal coronary angioplasty was performed and two-drug eluting stents were placed.

\section{Operative Technique}

After sternotomy during HTX in 2008, we performed a right minithoracotomy with videoscopy and cardiopulmonary bypass through peripheral right femoral cannulation. Transesophageal echocardiography confirmed a subvalvular

\footnotetext{
(C) 2019 Georg Thieme Verlag KG Stuttgart · New York
}

License terms

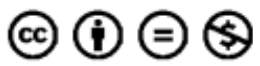




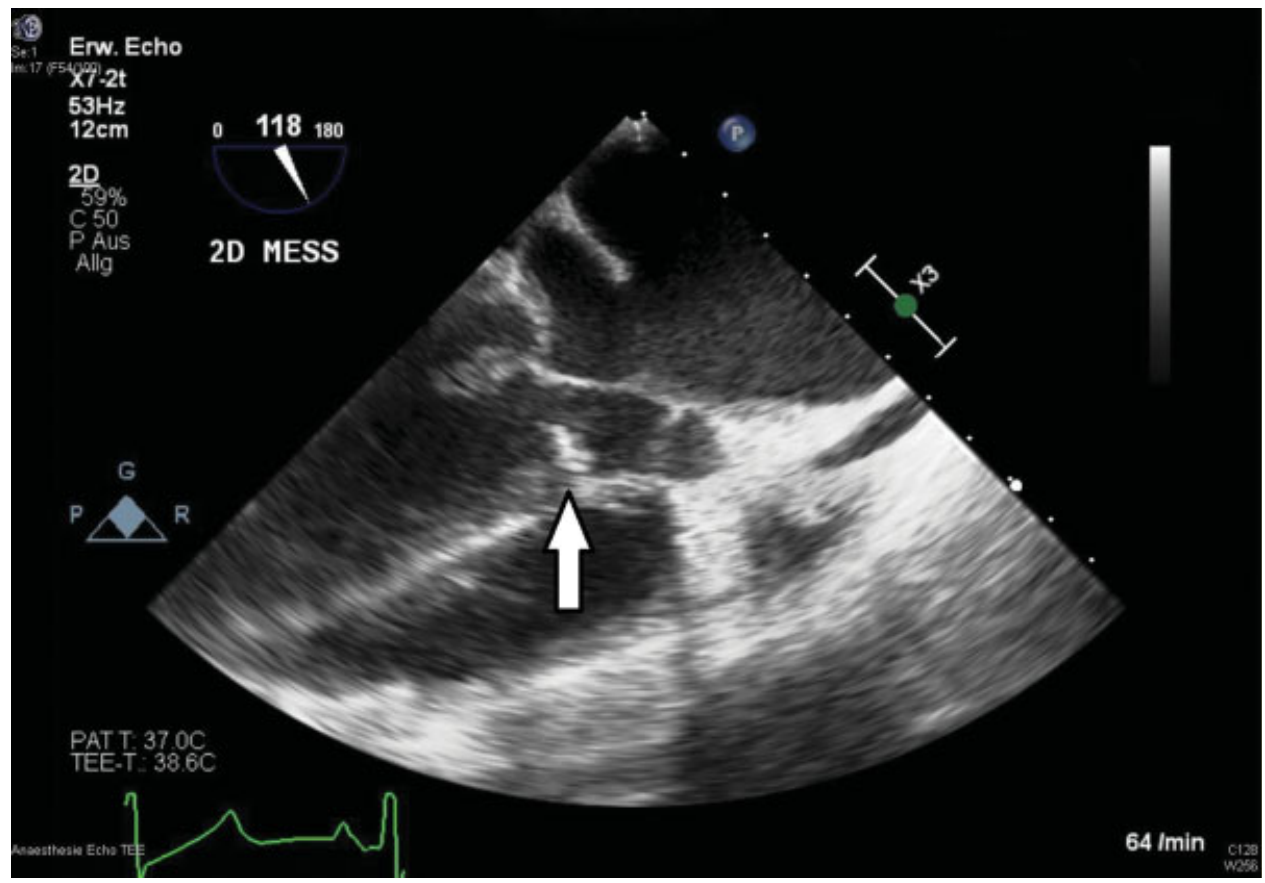

Fig. 1 Intraoperative transoesophageal echocardiography of a subvalvular membrane in the left ventricular outflow tract (marked by an arrow), measuring $1.0 \times 0.5 \mathrm{~cm}$, with probable connection to the anterior mitral valve leaflet.

membrane in the LVOT, measuring $1.0 \times 0.5 \mathrm{~cm}$, with probable connection to the anterior mitral leaflet ( - Fig. 1). Invasive PPG in the LVOT was $25 \mathrm{~mm} \mathrm{Hg}$.

The fifth intercostal space was opened through minimal skin incision in the submammary crease. Through the occlusion catheter (IntraClude Intra-Aortic Occlusion Device, Edwards Lifesciences Corporation), aortic cross-clamping, antegrade cardioplegia, and aortic root venting were performed. ${ }^{2}$ Cardiac arrest was established by 2-L Custodiol (Dr. Franz Köhler Chemie $\mathrm{GmbH}$ ) after inflation of the IntraClude balloon.

Incision of the left atrium was followed by excision of the MV and the subvalvular membrane ( - Fig. 2). MV leaflets showed severe endocardial thickening. The subvalvular membrane of the LVOT was identified and excised as well. Due to the rigidity of the endocardial tissue, MV replacement with a biological prosthesis was agreed upon in accordance with previous agreement of the patient. We implanted a 27$\mathrm{mm}$ Hancock II MV prosthesis (Medtronic).

Aortic cross-clamp time was 81 minutes, and overall CBP time was 145 minutes.

\section{Postoperative Course}

After 1 day in intensive care unit and 5 days in the intermediate care ward, the patient was discharged on postoperative day 10.

Histological work-up showed hyaline and myxomatous degeneration with calciferous parts. There were no signs of previous endocarditis.

\section{Discussion}

Cases of MV dysfunction after HTX are rare. There are only a few studies and case reports that mention MV repair, mainly due to MV regurgitation. In a retrospective study, Goekler et al first described MV replacement for stenosis after hemodialysis for 2 years following HTX. ${ }^{3}$ Our case reports the first study published on minimally invasive MV replacement for valve stenosis with intraluminal aortic clamping. Despite worldwide long experience in the field of HTX, numbers of secondary surgical interventions in HTX recipients are scarce. Overall prevalence of reoperations after successful HTX is estimated to

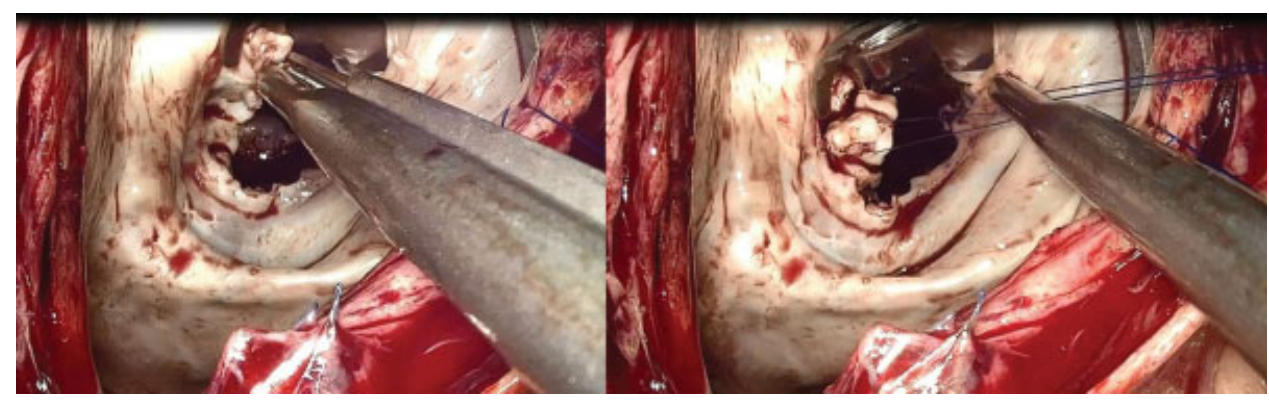

Fig. 2 Excision of the subvalvular membrane through the left atrium (filmed by videoscopy). 
be between 2 and 5\%. Even high-volume centers describe only a small number of reoperations. ${ }^{3-5}$

Considering the high possibility of adhesions from preceding HTX, the hazard of traumatic or iatrogenic injuries can be reduced by avoiding resternotomy. After aortic and pulmonary artery anastomosis during HTX, the chances for severe adhesions are more relevant. In our opinion, intraluminal aortic clamping via a three-lumen catheter to circumvent severe adhesions between the aorta and the pulmonary artery after great vessel anastomosis during HTX is a safe option. Main complications using intraluminal clamping are described as aortic dissection, iliac artery injury, and cerebrovascular events. Nevertheless, minimally invasive valve surgery is considered being a safe and effective method in short- and long-term results, especially in redo operations. ${ }^{6}$

In a large retrospective study, Pasca et al showed that renal insufficiency is a risk factor for degenerative mitral stenosis. ${ }^{7}$ In patients suffering from MV calcification, kidney disease is more common in patients younger than 50 years. ${ }^{8}$ We consider the renal insufficiency of our patient due to immunosuppression therapy as the main cause for the aggravation of MV degeneration over a time period of 10 years.

This case was discussed in our multidisciplinary team of cardiac surgeons and cardiologists before indication for reoperation was decided upon after conventional catheter approach was unsuccessful.

\section{Conclusion}

We report the first case of successful MV replacement in an HTX recipient through minimally invasive right thoracotomy using aortic endoclamp. Considering the lack of international recommendations and guidelines for this specific patient cohort, we emphasize the multidisciplinary approach in treating these patients who need secondary cardiac interventions after HTX.

Funding

No funding was obtained for this article.

Conflict of Interest

The authors report no conflict of interest or relevant disclosures.

\section{References}

1 Lund LH, Khush KK, Cherikh WS, et al; International Society for Heart and Lung Transplantation. The Registry of the International Society for Heart and Lung Transplantation: Thirty-fourth Adult Heart Transplantation Report-2017; Focus Theme: Allograft ischemic time. J Heart Lung Transplant 2017;36(10):1037-1046

2 Wigfield $\mathrm{CH}$, Lewis A, Parry G, Dark JH. Mitral valve dysfunction and repair following orthotopic heart transplantation: a case report. Transplant Proc 2008;40(05):1796-1797

3 Goekler J, Zuckermann A, Osorio E, et al. cardiac surgery after heart transplantation: elective operation or last exit strategy? Transplant Direct 2017;3(10):e209

4 Goerler H, Simon A, Warnecke G, et al. Cardiac surgery late after heart transplantation: a safe and effective treatment option. J Thorac Cardiovasc Surg 2010;140(02):433-439

5 Holmes TR, Jansz PC, Spratt P, et al. Cardiac surgery is successful in heart transplant recipients. Heart Lung Circ 2014;23(08): 703-710

6 Marullo AG, Irace FG, Vitulli P, et al. Recent developments in minimally invasive cardiac surgery: evolution or revolution? BioMed Res Int 2015;2015:483025

7 Pasca I, Dang P, Tyagi G, Pai RG. Survival in patients with degenerative mitral stenosis: results from a large retrospective cohort study. J Am Soc Echocardiogr 2016;29(05):461-469

8 Weissler-Snir A, Weisenberg D, Natanzon S, et al. Clinical and echocardiographic features of mitral annular calcium in patients aged $\leq 50$ years. Am J Cardiol 2015;116(09):1447-1450 